\title{
ДИНАМІКА НИЗЬКОЕНЕРГЕТИЧНОЇ ЛАЗЕРНОЇ ПЛАЗМИ ОЛОВА
}

\author{
М.П. ЧУЧМАН, Л.В. МЕСАРОШ, О.К. ШУАІБОВ
}

удк 533.9 Ужгородський національний університет

(2012 (Вул. Підгірна, 46, Ужсгород 88000; e-mail: chuchman@univ. uzhgorod.ua)

Вивчення початкових етапів розширення ерозійної лазерної плазми олова проведено методом емісійної спектроскопії з високим часовим розділенням. Досліджено часові залежності заселеності збуджених станів атомів та іонів олова. Проведено оцінку часів рекомбінації іонів, встановлено залежності від часу для температури і концентрації електронів лазерної плазми на відстанях 1 і 7 мм від мішені.

\section{1. Вступ}

Плазмовий факел з твердотільної мішені, який утворюється потужним лазерним випромінюванням, має широке коло застосувань $[1,2]$. Так, лазерна плазма олова є джерелом м'якого рентгенівського випромінювання і перспективна для фотолітографії наступного покоління [3-6].

$\mathrm{У}$ роботах $[7,8]$ наводяться результати дослідження процесів у лазерній плазмі олова. Основною метою цих робіт були: оптимізація параметрів плазми і оптимізації плазмохімічних реакцій у лазерному факелі з метою отримання тонких плівок різного складу. Тому дослідження лазерного факела олова є актуальним, а метод емісійної спектроскопії дає необхідну інформацію для аналізу процесів у такій плазмі.

Метою нашої роботи є дослідження часових характеристик лазерної плазми олова методом емісійної спектроскопї.

\section{2. Експериментальна установка}

Для отримання лазерної плазми використовувався імпульсно-періодичний лазер ЛТИПЧ-5, який працював у режимі модульованої добротності (12 Гц, 1064 нм, 20 нс, $4 \cdot 10^{8} \mathrm{~B}$ т $\left./ \mathrm{cm}^{2}\right)$. Мішень з чистого олова встановлювалася у вакуумній камері при тиску залишкових газів 6 Па.

Випромінювання аналізувалося за допомогою монохроматора МДР-2 з дифракційною граткою 1200 штр./мм у спектральній області 200-600 нм. Розділення монохроматора за довжинами хвиль становило 0,2 нм. Реєстрація оптичних і часових характеристик випромінювання лазерної плазми проводилася за допомогою: монохроматора МДР-2, фотопомножувача ФОТОН і осцилографа C1-99. Точність виміру інтенсивності була не гіршою $10 \%$. Розшифровка спектрів проводилася за даними довідників $[9,10]$.

\section{3. Обговорення результатів}

Основними процесами, що призводять до утворення збуджених станів атомів та іонів Sn у плазмі лазерного факела, яка розширюється у вакуум або залишковий газ, виступає діелектронна рекомбінація та теплові процеси:

$$
\begin{aligned}
& \mathrm{Sn}^{+2(o)}+e+e \rightarrow \mathrm{Sn}^{+1(*)}+e^{\prime} \\
& \mathrm{Sn}^{+1(o)}+e+e \rightarrow \mathrm{Sn}^{*}+e^{\prime} \\
& \mathrm{Sn}^{o}+e^{\prime} \rightarrow \mathrm{Sn}^{*}+e .
\end{aligned}
$$

Суть цих процесів полягає в захопленні іоном в основному стані електрона, а надлишок енергії виноситься другим електроном. Після цього утворюється іон меншої зарядності у верхньому збудженому стані. Взаємодія швидких електронів з атомами в основному стані приводитиме до утворення атомів олова, що знаходяться в нижніх збуджених станах. 

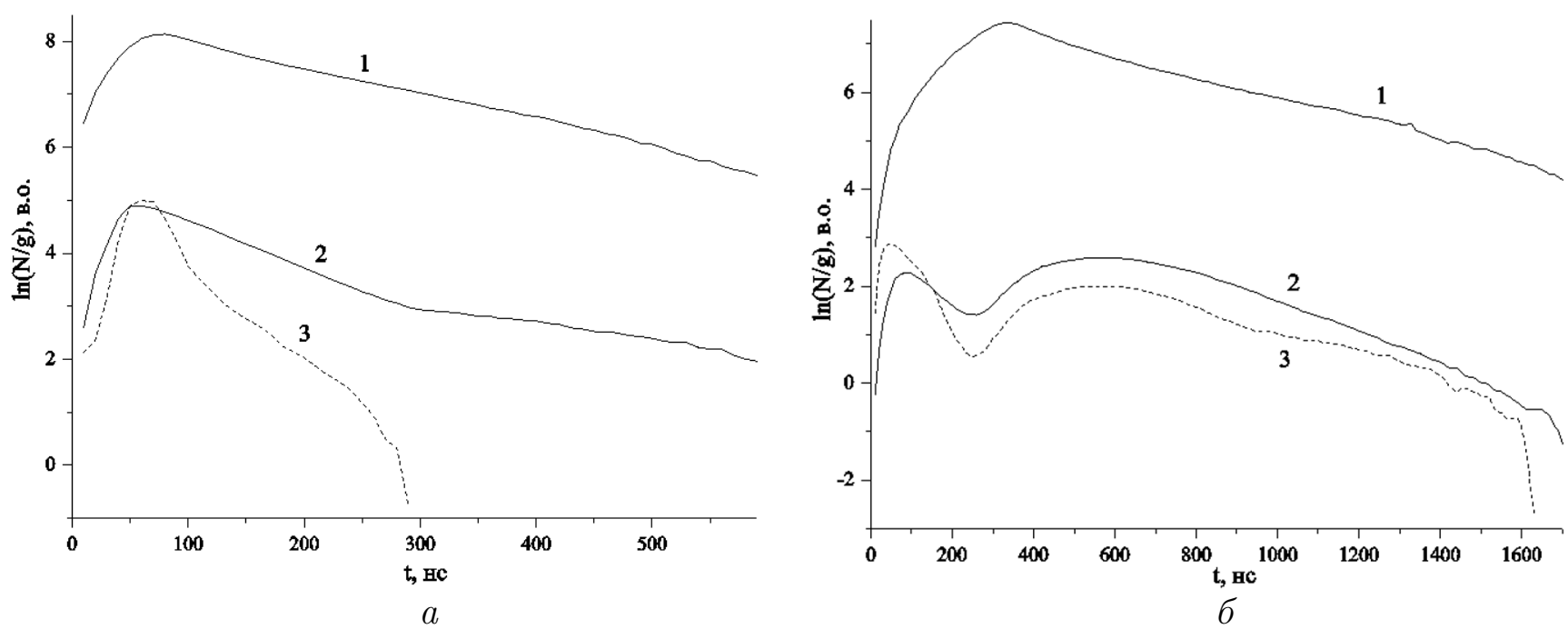

Рис. 1. Динаміка заселення збуджених станів атомів та іонів олова з енергіями: 1 - 4,29 еВ; 2 - 5,52 еВ; 3 - 11,07 еВ на відстанях 1 мм (а) та 7 мм (б) від мішені

Т а б л ц я 1. Параметри для аналізу часових залежностей інтенсивності випромінювання лазерної плазми олова на відстанях 1 та 7 мм від мішені

\begin{tabular}{|c|c|c|c|c|c|c|c|c|}
\hline № & $\lambda$, нм & $A, 10^{8} \mathrm{c}^{-1}$ & Атом, іон & $E_{\mathrm{H}}, \mathrm{eB}$ & $\mathrm{Tepm}_{\mathbf{H}}$ & $E_{\mathrm{B}}, \mathrm{eB}$ & $\mathrm{Tepm}_{\mathrm{B}}$ & $g$ \\
\hline 1 & 303,4 & 1,51 & Sn I & 0,21 & $5 \mathrm{p}^{2}{ }^{3} \mathrm{P}_{1}$ & 4,29 & $\mathrm{p} 6 \mathrm{~s}^{3} \mathrm{P}_{0}$ & 1 \\
\hline 2 & 242,9 & 1,77 & Sn I & 0,43 & $5 \mathrm{p}^{2}{ }^{3} \mathrm{P}_{2}$ & 5,52 & $\mathrm{p} 5 \mathrm{~d}{ }^{3} \mathrm{D}_{3}$ & 7 \\
\hline 3 & 328,3 & 1 & Sn II & 7,29 & $5 \mathrm{~s} 5 \mathrm{p}^{2}{ }^{2} \mathrm{D}_{3 / 2}$ & 11,07 & $5 \mathrm{~s}^{2} 4 \mathrm{f}^{2} \mathrm{~F}_{5 / 2}$ & 6 \\
\hline
\end{tabular}

Зі значень інтенсивності на осцилограмах інтенсивності спектральних ліній було визначено заселеності збуджених станів атомів та іонів:

$$
\frac{N}{g}=\frac{I \lambda}{A g},
$$

де $N$ - заселеність рівня, $g$ - статистична вага, $\lambda-$ довжина хвилі, $I$ - інтенсивність, $A$ - ймовірність переходу. Температура електронів $\left(T_{e}\right)$ у лазерній плазмі визначалася графічним методом після побудови розподілу Больцмана у вигляді залежності $\ln (N / g)$ від енергії рівня. Концентрація електронів $\left(n_{e}\right)$ у лазерній плазмі олова обчислювалась за допомогою співвідношення між часом рекомбінації і концентрацією електронів при відомій температурі:

$n_{e}=\left(8,75 \cdot 10^{-27} z^{3} t_{r} T_{e}^{-9 / 2}\right)^{-1 / 2}$,

де $z$ - заряд іона, який рекомбінує, $t_{r}$ - час рекомбінації. Детальніше методику дослідження вимірів параметрів лазерної плазми наведено в [11].

На рис. 1 подано зміну заселеності збуджених станів атомів і іонів олова від часу. Дані для аналізу часових залежностей інтенсивності випромінювання лазерної плазми олова на відстані 1 і 7 мм від мішені наведено в табл. 1. На відстані 1 мм від мішені заселеності збуджених станів ростуть до часу $t \sim 70 \mathrm{Hc}$, після чого зменшуються, причому характер спаду для збуджених станів різних енергій є різним. Основною особливістю є сповільнення спаду заселеності верхніх збуджених станів атомів після різкого зменшення заселеності іонів, яке спостерігається при $t \sim 250-$ 300 нс. Внаслідок специфіки зміни концентрації частинок у плазмі, її параметрів і значного прояву тричастинкової рекомбінації, можна пояснити зміну заселеності верхніх і нижніх збуджених станів. Характер зміни заселеності верхніх збуджених станів атомів, у той час, коли різко спадає заселеність збуджених станів іонів (рис. 1), може відображати посилення утворення таких станів при рекомбінації. На рис. 1 найбільш складний вигляд має зменшення заселеності збуджених станів іонів, для якого спостерігається три різні ділянки зміни заселеності від часу. Для нижніх збуджених станів атомів зміна заселеності є лінійною за час спостереження, після появи максимуму.

На відстані 7 мм від мішені максимум заселеності збуджених станів іонів досягається при часі спостереження $t \sim 50$ нс, для верхніх збуджених станів атомів 

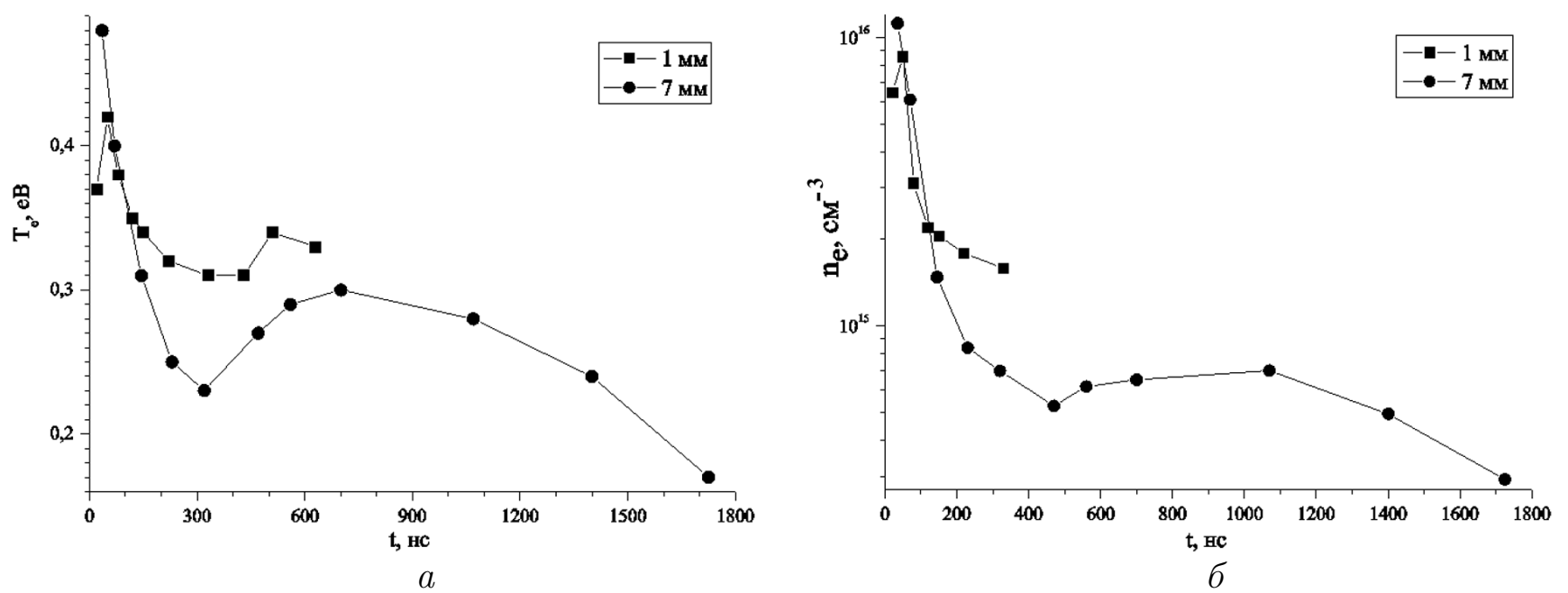

Рис. 2. Залежності температури (a) та концентрації (б) електронів від часу в лазерній плазмі олова

характер зміни заселеності подібний, хоча максимум з'являється при $t \sim 100$ нс, але їх мінімуми збігаються і спостерігаються при $t \sim 250$ нс. Характер спаду для заселенностей збуджених станів атомів різний при спостереженні випромінювання іонів і після того, як випромінювання іонів вже не спостерігається.

На відстані 7 мм від мішені, після часу 1600 нс, заселеність збуджених станів іонів різко зменшується. Також зменшується заселеність збуджених станів атомів, тим повільніше, чим менша енергія нижнього збудженого стану. Заселеність збудженого стану атомів з меншою енергією зростає до $t \sim 350$ 400 нс, коли досягає максимуму і далі плавно спадає.

Після часу $t \sim 300$ нс для збуджених станів іонів і верхнього збудженого стану атомів спостерігається повторне збільшення заселеності рівнів. Другий максимум спостерігається при $t \sim 550$ нс. Максимум заселеності верхніх збуджених станів іонів на відстані 1 і 7 мм від мішені спостерігається майже в однаковий час. Тобто, швидкість поширення іонної компоненти на передньому фронті змінюється мало. Тому на відстані 1 мм від мішені концентраційний профіль відповідає параметрам плазми до часу 300 нс, на відстані 7 мм максимум для випромінювальних переходів 3 нижніх збуджених станів не відображується коли досягається перший максимум для випромінювання при переходах з верхніх збуджених станів атомів і збуджених станів іонів. Тому нижні збуджені стани атомів, які утворяться внаслідок теплових процесів, змінюватимуть в часі свою поведінку, але вже відображуючи специфіку утворення ударної хвилі. Тоді як для верхніх збуджених станів атомів відображається рекомбінаційний механізм утворення та їх випромінювальні переходи добре повторюють залежність інтенсивності випромінювання іонів від часу.

На рис. 2 наведено часові залежності температури і концентрації електронів лазерної плазми олова. Зміна температури електронів характеризувалася двома максимумами в часі. Перший максимум температури електронів спостерігається на передньому фронті плазми $t=30-50$ нс. Максимальне значення температури електронів на часовій залежності становило для 1 і 7 мм від мішені 0,42 еВ i, відповідно, 0,48 eB. Другий максимум добре виражений на відстані 7 мм від мішені. Він спостерігається при часі від 300 до 1800 нс. Максимальне значення температури в другому максимумі становить 0,3 еВ при $t \sim 700$ нс. При відстані 1 мм від мішені, другий максимум менше виражений, спостерігається при часі 500 нс і його величина досягає $0,34 \mathrm{eB}$.

Загальний діапазон зміни температури електронів на відстані 1 мм від мішені становить 0,42-0,3 еВ протягом часу $650 \mathrm{Hc}$, а при відстані 7 мм від мішені 0,48-0,17 еВ протягом 1800 нс. Згідно з адіабатичною моделлю на різних відстанях від мішені об'єми плазми різні, при менших значеннях об'єму температура вища. Падіння температури після досягнення першого максимуму на 7 мм від мішені є різкішим. Автори [12] показують, що при невеликих відстанях від мішені $(<4$ мм) часовий розподіл випромінювання лазерного факела характеризується одним максимумом, а другий з'являється лише на великих відстанях. Нами в [13] показано, що таким відстаням від мішені відповідає формування ударної хвилі. Отже, перший максимум на наших залежностях характеризує плазму до початку дії на неї газодинамічних ефектів, а 


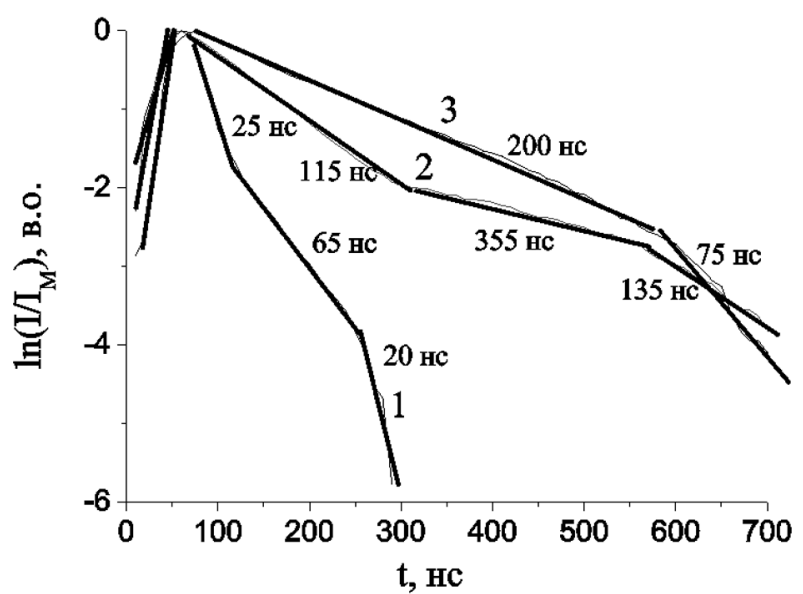

$a$

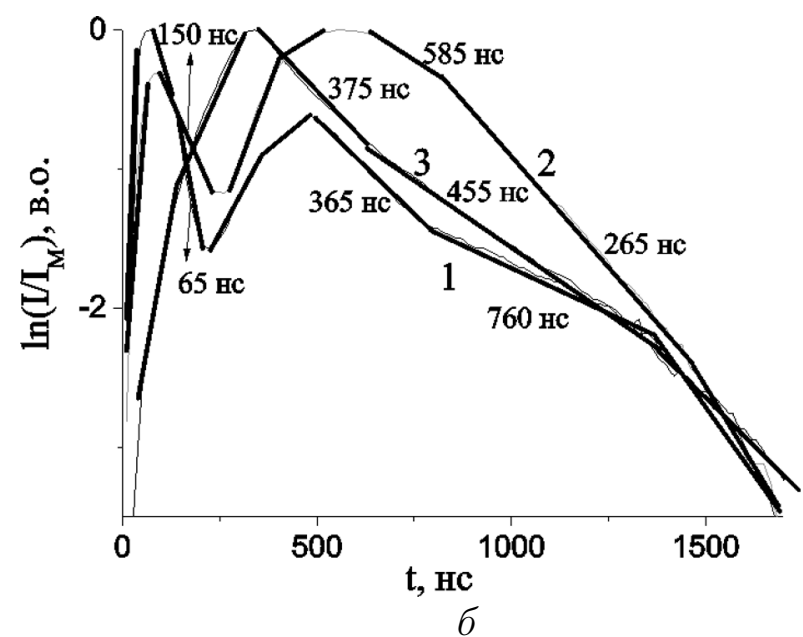

$\sigma$

Рис. 3. Залежності логарифмів нормованих інтенсивностей спектральних ліній атомів та іонів олова від часу: 1 - 328,3 нм Sn II, $E_{\mathrm{B}}=11,07 \mathrm{eB} ; 2-242,9$ нм Sn I, $E_{\mathrm{B}}=5,52 \mathrm{eB}, 3-303,4$ нм Sn I, $E_{\mathrm{B}}=4,29$ еВ на відстанях 1 мм (a) та 7 мм (б) від мішені

другий максимум, ймовірно, є наслідком формування ударної хвилі.

3 розгляду зміни в часі концентрації електронів $\left(n_{e}\right)$ випливає, що на відстані 1 мм від мішені максимум спостерігається при $t \sim 50$ нс і становить $8,6 \cdot 10^{15} \mathrm{~cm}^{-3}$, а на відстані 7 мм від мішені спостерігається перший максимум при часі $40 \mathrm{Hc} \mathrm{i} 1 \cdot 10^{16} \mathrm{~cm}^{-3}$, після чого концентрація часток плавно спадає до $5,3 \cdot 10^{14} \mathrm{~cm}^{-3}$, що спостерігається при $t \sim 465 \mathrm{нс.}$ Другий максимум спостерігається при 1070 нс, йому відповідає концентрація електронів $7,1 \cdot 10^{14} \mathrm{~cm}^{-3}$, яка надалі спадає до $2,9 \cdot 10^{14} \mathrm{~cm}^{-3}$ при $t=1725 \mathrm{нс} \mathrm{[14].}$ Другий максимум відображає газодинамічні процеси у плазмі. Передня частина лазерного факела взаємодіє з навколишнім газом, що є причиною зменшення і1ї швидкості. Другий максимум може бути викликаний виникненням турбулентності, при якій кінетична енергія атомів та іонів перетвориться на енергію збудження. 3 аналізу цих результатів випливає, що із зростанням відстані від мішені концентрація і температура електронів спадає, але із збільшенням потужності, яка вноситься в мішень, ці параметри теж збільшуються.

По залежності інтенсивності спектральної лінії іона із зарядом $z$ від часу можна визначити час рекомбінації іонів заряду $z+1$. При цьому час рекомбінації дорівнює тангенсу кута нахилу прямої, яку отримують при побудові залежності логарифма інтенсивності $(I)$ від часу $(t)$ :

$t_{r}=\frac{\Delta t}{\Delta \ln \frac{I}{I_{M}}}$, де $I_{M}$ - максимальне значення інтенсивності. Особливості зміни інтенсивності в часі дають додаткову інформацію про хід фізичних процесів у лазерній плазмі. Методика такого аналізу описана в [15]. Із рис. 3 видно, що на відстані 1 мм від мішені в діапазоні часу 100-200 нс час рекомбінації зростає до $t=65 \mathrm{Hc}$, а далі при часі $t>250$ нс становить 20 нс.

Час рекомбінації кілька разів стрибком змінюється протягом часу спостереження. На відстані 7 мм від мішені свічення іонів і атомів спостерігається до часу 1500 нс. На цій відстані від мішені час рекомбінації для однозарядних іонів олова становив 150 нс, а для двозарядних іонів - 65 нс при $t=100-250$ нс. При часі спостереження 500-700 нс для однозарядних іонів час рекомбінації становив 585 нс, а для двозарядних -365 нс [16].

Час рекомбінації іонів залежить від температури та концентрації електронів і виражається таким співвідношенням: $t_{r} \sim T_{e}^{9 / 2} / n_{e}^{2}[15]$. Побудувавши логарифмічні залежності температури, концентрації електронів і заселеності рівня, що відповідає збудженому стану цього іона, можна побачити, що температура і заселеність також стрибкоподібно змінюватимуться при $t=100-120$ нс, 200-220 нс. В інтервалі часів між цими значеннями температура і заселеність змінюватимуться лінійно. У разі концентрації електронів стрибок на лінійній залежності спостерігається при $t=120$ нс.

Таким чином, особливості зміни часу рекомбінації пов'язані зі зміною температури електронів і концентрацією іонів. Причиною цього можуть бути газодинамічні процеси, що визначають рух і розшире- 
ння плазмового факела. У точках, що відповідають стрибкам, можливі зміни в характерних етапах розширення плазмового факела. На логарифмічній залежності зміни заселеності верхніх збуджених станів атомів олова від часу видно лінійну залежність із стрибком при часі $\sim 300$ нс. Специфічна зміна концентраційного профілю в часі для атомів і іонів пояснюється тим, що іони знаходяться в центрі плазмового згустку, а атоми на периферії, тому для них по різному проявлятимуться особливість руху і динаміка розширення плазми. У центральній частині плазми імовірнішим буде відображення специфіки концентраційного профілю, що утворився при виникненні плазми. А для атомів, в зовнішньому шарі плазми, важливішу роль відіграватимуть процеси взаємодії з навколишнім газом.

Якби мали місце теплові процеси, то зміна інтенсивності проявилася б однаково для усіх збуджених станів з усіма енергіями, що добре видно на відстані 7 мм від мішені.

На задньому фронті час рекомбінації однозарядних іонів становить 115 нс при часах до $t=250 \mathrm{нс}, 355$ нс становить до часу $t=550$ нс і 135 нс після нього. Після часу 300 нс значний вплив має зміна температури електронів, оскільки концентрація електронів та іонів змінюється набагато повільніше.

На відстані 1 мм від мішені інтенсивність випромінювання при переходах з нижніх збуджених станів змінюється швидше, ніж інтенсивність випромінювання при переходах з верхніх збуджених станів після часу 300 нс. Це вказуе на рекомбінаційні процеси, які відбуваються досить повільно на задньому фронті плазми і приводять до зменшення швидкості спаду інтенсивності атомів, що утворюються в результаті цих процесів. На задньому фронті плазми швидкість руху буде значно нижчою, ніж на передньому.

Мінімальне значення температури електронів на відстані 7 мм від мішені спостерігалося при часі $t=$ 320 нс, а для концентрації електронів при $t=470$ нс. Спостерігається просторовий перерозподіл частинок і зміна руху від напрямленого до хаотичного з виділенням енергії внаслідок рекомбінаційних процесів та перемішування.

Спад заселеності іонних станів сповільнюється коли має місце максимум для концентрації електронів. При часі $t=700$ нс з'являється другий максимум для температури електронів і приблизно так само для концентрації електронів. На відстані 7 мм від мішені для мінімального значення температури електронів при $t \sim 320$ нс спостерігається максимальна заселеність нижніх збуджених станів (при часі $t \sim 335$ нс).
$\mathrm{У}$ той час коли концентрація електронів зростає (до часу $t=1200$ нс), температура електронів навпаки, спадає. Імовірним є те, що внаслідок утворення ударної хвилі температура на передньому фронті знаходиться в максимумі, і що концентрації електронів збільшуються внаслідок появи енергії через рекомбінаційні процеси та зміни характеру руху. Частинки з високими значеннями кінетичної енергії при русі зазнають зіткнень і стає можливою їх іонізація.

Максимальна заселеність нижнього збудженого стану атома спостерігається при часі $t=75$ нс для 1 мм від мішені, а на 7 мм від мішені при часі $t=$ 335 нс. Коли плазма розширюється в режимі ударної хвилі заселеність рівнів не збігається з просторовим розподілом температури і концентрації електронів.

\section{4. Висновки}

Емісійна спектроскопія лазерного факела олова дозволила вивчити динаміку заселеності збуджених станів атомів та іонів олова. Встановлено, що зміни заселеності верхніх і нижніх збуджених станів можна пояснити специфікою зміни концентрації частинок в плазмі, і зміною їі параметрів.

Загальний діапазон зміни температури електронів на відстані 1 мм від мішені становить 0,42-0,3 еВ протягом часу 650 нс. При відстані 7 мм від мішені 0,480,17 еВ впродовж часу 1800 нс.

На відстані 1 мм від мішені максимум концентрації електронів спостерігається при 49 нс і становить $8,6 \cdot 10^{15} \mathrm{~cm}^{-3}$, а на відстані 7 мм від мішені спостерігаються два максимуми: перший при часі 40 нс і $1 \cdot 10^{16} \mathrm{~cm}^{-3}$, другий максимум спостерігається при 1070 нс, йому відповідає концентрація електронів $7,1 \cdot 10^{14} \mathrm{~cm}^{-3}$. При утворенні ударної хвилі температура на передньому фронті плазми знаходиться в максимумі, а концентрація електронів збільшується внаслідок виділення енергії при рекомбінаційних процесах і змінах характеру розширення лазерного факела.

Визначено час рекомбінації іонів на відстанях 1 i 7 мм від мішені. На відстані 1 мм від мішені в діапазоні часу спостереження 100-200 нс час рекомбінації для двозарядних іонів зростає від 30 до 65 нс, далі при часі більше 250 нс становить 20 нс, а для однозарядних, у наведеному вище часовому інтервалі, часи рекомбінації становлять 115 і 355 нс відповідно. Час рекомбінації кілька разів стрибком змінюється за час спостереження, в точках, що відповідають стрибкам, можливі зміни в характерних етапах розширення плазмового факела. Рекомбінаційні про- 
цеси, які відбуваються досить повільно на задньому фронті плазми, приводять до зменшення швидкості спаду інтенсивності випромінювання атомів, що утворюються в результаті таких процесів.

На відстані 7 мм від мішені часи рекомбінації становлять: для однозарядних іонів - 150 нс, а для двозарядних - 65 нс при часі спостереження 100-250 нс. При часах спостереження 500-700 нс для однозарядних іонів час рекомбінації становить 585 нс, а для двозарядних - 365 нс.

1. N.H. Bings, A. Bogaerts, and A.C. Broekaert, At. Spectr. Anal. Chem. 76, 3313 (2004).

2. R.W. Coons, D. Campos, M. Crank, S.S. Harilal, and A. Hassanein, Proc. SPIE 7636, 37 (2010).

3. R.F. Wood, K.R. Chen, J.N. Leboeuf, A.A. Puretzky, and D.B. Geohegan, Phys. Rev. Lett. 79, 1571 (1997).

4. P.J. Silverman, J. Microlithogr. Microfabric. Microsyst. 4, 011006 (2005).

5. S. Harilal, B. O'Shay, and S.M. Tillack, J. Appl. Phys. 98, 1 (2005).

6. J.P. Allain, A. Hassanein, M. Nieto., V. Titov, P. Plotkin, E. Hinson, B.J. Rice, R. Bristol, D. Rokusek, W. Lytle, B.J. Heuser, M.C. Allain, H. Ju, and C. Chrobak, Proc. SPIE 5751, 1110 (2005).

7. C. Ristoscu, L. Cultrera, A. Dima, A. Perrone, R. Cutting, A. Busiakiewiczd, Z. Klusek, P.K. Datta, and S.R. Rose, Appl. Surf. Sci. 247, 95 (2005).

8. P.A. Fernandes, P.M. Salome, and A.F. da Cunha, J. Phys. D 43, 215403 (2010).

9. А.Н. Зайдель, В.К. Прокофьев, С.М. Райский, В.А. Славный, Е.Я. Шрейдер, Таблицы спектралъных линий (Наука, Москва, 1969).

10. P.L. Smith, C. Heise, J.R. Esmond, and R.L. Kurucz, Atomic Spectral Line Database from CD-ROM (Smithsonian Astrophysical Observatory, Cambridge, 1995).

11. М.П. Чучман, А.К. Шуаибов, Физика плазмы 34, 12 (2008).

12. S. Harilal, B. O'Shay, Y. Tao, and M.S. Tillack, J. Appl. Phys. 99, 083303 (2006).

13. Л.В. Месарош, М.П. Чучман, О.К. Шуаібов, I.Е. Качер, Науковий вісник Ужгородського університету, серія Фізика 27, 60 (2010).
14. Л.В. Месарош, О.К. Шуаібов, Тез. допов. IЕФ-2011 Міжнародна конференція молодих учених і аспірантів, (Мистецька Лінія, Ужгород, 2011).

15. Л.Т. Сухов, Лазерный спектралъный анализ (Новосибирск, Наука, 1990).

16. Л.В. Месарош, О.К. Шуаібов, Тез. допов. Лазерні технології. Лазери та їх застосування. Всеукраӥнсъка науково-технічна конферениія з міжнародною участю (Редакційно-видавничий відділ Дрогобицького державного педагогічного університету імені Івана Франка, Дрогобич, 2011).

Одержано 02.03.12

\section{ДИНАМИКА НИЗКОЭНЕРГЕТИЧЕСКОЙ ЛАЗЕРНОЙ ПЛАЗМЫ ОЛОВА}

М.П. Чучман, Л.В. Месарош, А.К. Шуаибов

Р е $з$ ю м е

Методом эмиссионной спектроскопии с высоким временным разрешением проведено изучение начальных этапов расширения эрозионной лазерной плазмы олова. Исследованы временные зависимости заселенности возбужденных состояний атомов и ионов олова. Проведены оценки времен рекомбинаций ионов, установлены зависимости от времени для температуры и концентрации электронов на расстояниях 1 и 7 мм от мишени.

\section{DYNAMICS OF LOW-ENERGY LASER-PRODUCED}

\section{TIN PLASMA}

M.P. Chuchman, L.V. Mesarosh, A.K. Shuaibov

Uzhgorod National University

(46, Pidgirna Str., Uzhgorod 88000, Ukraine;

e-mail: chuchman@univ.uzhgorod.ua)

$\mathrm{S}$ u $\mathrm{m} \mathrm{m}$ a r y

Emission spectroscopy with a high temporal resolution is used to study the initial expansion stages of the erosive laser-produced tin plasma. The time dependences of the population of excited states of tin atoms and ions are examined. The time of ion recombination was evaluated, and the time dependences of the electron temperature and concentration at distances of 1 and $7 \mathrm{~mm}$ from the target are determined. 